\title{
Uma proposta de reforma para a ética jornalística ${ }^{1}$
}

\author{
WARD, Stephen J.A. Disrupting Journalism Ethics. Radical Change on the \\ Frontier of Digital Media. London/New York: Routledgle, 2019.
}

\section{Rogério Christofoletti}

Professor do Departamento e do Programa de Pós-Graduação em Jornalismo da UFSC, pesquisador do $\mathrm{CNPq}$ e um dos coordenadores do Observatório da Ética Jornalística (objETHOS).

E-mail: rogerio.christofoletti@ ufsc.br

${ }^{1}$ Este livro foi resenhado a partir de exemplar enviado pela editora. Isso não produziu viés tendencioso nem interferiu na independência da análise.
"Disruptivo" tem sido um dos adjetivos mais vocalizados em eventos sobre avanços tecnológicos na mídia e suas inadiáveis mudanças sociais. A palavra da moda tenta demarcar o alcance e a intensidade de rupturas com práticas, ideias e hábitos que estavam consolidados até muito pouco tempo atrás. Assim, uma atitude disruptiva rompe padrões, sinaliza outros parâmetros e induz a novas ações e reações. Tem a ver com novidade, mas não se trata só de substituir ou sobrepor. Disruptivo é aquilo que força uma reinvenção porque denuncia insuficiência ou obsolescência. É, então, um cenário de instabilidades que nos desorientam e que impõem uma lógica binária: adaptação ou extinção.

A palavra-fetiche circula com facilidade na atmosfera jornalística atual, rarefeita de certezas e ao mesmo tempo carregada pelo enxofre da crise na indústria. Disrupting Journalism Ethics, de Stephen J. A. Ward, atrai as angústias e a efervescência desses tempos para refletir sobre o que resta da ética jornalística nas nossas sociedades convulsivamente hiper-conectadas. Se o jornalismo já não é mais o que pensávamos e se nossos princípios erodiram, o raciocínio mais imediato é imaginar que tudo se perdeu. Ward sustenta a hipótese de que a ética jornalística precisa de uma profunda reforma conceitual, disposta a sacrificar algumas ideias que hoje já não mais se mantêm em pé e capaz de absorver noções mais oxigenadas das práticas profissionais emergentes. Numa expressão: uma ética jornalística disruptiva, consequência do abandono de alguns valores e da assunção de outros.

Do ponto de vista filosófico, Stephen Ward é um pragmatista, o que significa dizer que está preocupado em como os princípios vocalizados na ética jornalística são capazes de responder aos dilemas colocados na prática. Se em nosso mundo caótico e digital não conseguem dar conta desses dilemas, por que esses valores deveriam se manter?

A ideia de uma reforma dessas proporções não é nova sequer no pensamento de Ward. Ele já havia sinalizado essa direção com mais vigor e argumentação em Radical Media Ethics (2015), quando defendeu abertura da ética jornalística para uma participação maior da sociedade e para que novas formas de fazer jornalismo fossem absorvidas e consideradas. Segundo argumentou, quatro fatores contribuíam para se defender uma ética radical de mídia: a) depois dos grandes câmbios tecnológicos, econômicos e sociais, a mídia também deveria promover mudanças em sua ética; b) seus princípios ainda estavam muito abstratos; c) novas iniciativas jornalísticas não seguiam cartilhas morais tradicionais; d) a ética atual é muito restritiva e não engloba empreendimentos jornalísticos exteriores às redações con- 
${ }^{2}$ Um exemplo de aplicação do pensamento de Ward está em Paul (2017) que explora a ideia de "ética radical de mídia" para observar como dois coletivos brasileiros praticam atos de jornalismo (STEARNS,

2013).

${ }^{3} \mathrm{O}$ argumento de que a ética fechada do jornalismo precise se abrir aos públicos foi bem detalhado em Ward e Wasserman (2010; 2014 e 2015). vencionais. O embrião da reforma estava na atitude deliberada de questionar as raízes da própria ética, e é daí que vem o seu caráter "radical"2.

A paisagem disruptiva só amplia a aflição e a urgência de enfrentamento das certezas agora emboloradas. Se a ética jornalística é "o uso responsável da liberdade para publicar", a questão que Ward agora nos coloca é: o que é um jornalismo responsável em nosso mundo digital? Para tanto, o autor aborda, pelo menos, quatro pontos de apoio que ajudaram a escorar as regras deontológicas do jornalismo: dualismo, imparcialidade, patriotismo e esfera pública. Romper com a ética jornalística tradicional é, segundo Ward, afrontar uma ou mais ideologias dominantes na área, o que significa desconstruir e reconstruir a partir de escombros. Nem sempre a disrupção é necessária, ele reconhece, mas a contemporaneidade está recheada de razões que estimulam a desafiar nossas certezas. Se antes as redações se preocupavam com manipulação, independência, confidencialidade e verificação, agora, outros dilemas se apresentam, como os relacionados às questões identitárias, ao engajamento das comunidades, ao impacto global, às notícias falsas, à amplificação do ódio e de vozes intolerantes.

Se o jornalismo e seus públicos se habituaram às lógicas dualísticas apresentadas nos noticiários, agora, isso parece não dar conta da complexidade do mundo. Ward defende que o primeiro passo para romper com a ética jornalística tradicional é confrontar o modelo profissional objetivista, propondo esquemas alternativos. Isso significa renunciar ao binarismo que embasa o relato neutro dos fatos para adotar um holismo pragmático, capaz de considerar também as experiências e vivências do narrador, e sua agência na sociedade. Tal escolha remete ao papel do jornalista diante do mundo que não só assiste, mas nele também habita e nele também interage com seu público e outros grupos.

Contra o distanciamento dos fatos e personagens que o jornalista comumente se auto-impõe, Ward defende o engajamento profissional em torno de causas mais amplas, como a democracia ou uma esfera pública global. Assim, jornalistas podem assumir funções de ativistas quando atuam "democraticamente engajados" para advogar pela igualdade e o florescimento de seus públicos.

Outro plano abordado por Ward é o do patriotismo. No Brasil, as redações não são usinas de sua profusão como nos Estados Unidos, notadamente em períodos de conflitos armados ou atos terroristas. Talvez por isso, a ênfase de Ward nos pareça um tanto supervalorizada na discussão. De qualquer forma, em Disrupting Journalism Ethics, o autor reaproveita muito do que já havia externado numa coletânea que co-organizou há quase uma década quando formulou uma teoria normativa do patriotismo no jornalismo (WARD, 2010). Nela, o discurso patriótico sofre uma redução sensível em nome de um tom mais moderado, centrado na promoção de uma cultura cívica, leal ao bem comum e à humanidade. Note-se que o ajuste é estratégico e objetiva evitar extremismos que comprometam a qualidade das coberturas jornalísticas. Para combater o paroquialismo, Ward propõe o patriotismo global, esforço contributivo para o florescimento humano e para a dignidade das pessoas.

No penúltimo capítulo de seu livro, o autor demonstra sérias preocupações com a toxicidade da esfera pública atual. Ward acredita fortemente que jornalistas e grupos cívicos podem agir de forma colaborativa para combater notícias falsas, extremismos populistas e ataques de intolerância a minorias. "Romper, inventar e colaborar", enuncia Ward na forma de slogan, antes de listar um conjunto útil e amplo de questionamentos que podem reorientar as ações dos jornalistas diante desses desafios. A desintoxicação da esfera pública passa pelo que Ward chama de macro-resistência, que inclui a criação de uma coalizão global por acountability na mídia, pela compreensão de uma confiança digital, por letramento para a ética e uma maior participação do público nas discussões deontológicas do jornalismo ${ }^{3}$, 
por exemplo. Essa agenda, adverte, não é privativa de jornalistas ou indivíduos. Depende fundamentalmente de colaboração mútua e passa, inclusive, por esforços para reduzir as desigualdades sociais que ajudam a sustentar muitos dos males contemporâneos.

Ao final de Disrupting Journalism Ethics, Ward esboça o que seria a ética jornalística em um futuro próximo: com escopo global, orientada pela objetividade holística, preocupada com extremismos e contaminações que ameaçam a democracia e o florescimento humano, porosa à participação de não-jornalistas e comprometida a ensinar e a pesquisar. O autor reconhece que, nesse processo de depuração de valores, alguns princípios tendem a se manter fortes, como a verdade como imperativo para narrar os fatos e a necessidade de apurá-los antes de publicar.

Na jornada de pouco mais de 100 páginas de seu livro, Stephen Ward deixa diversos valores caros ao jornalismo pelo caminho, mas é preciso notar que não abre mão da ligação quase umbilical entre jornalismo e democracia. Reconheço que é um compromisso difícil de renunciar, mas radicalizando o próprio pensamento de Ward, talvez pudéssemos nos perguntar: justo agora, quando a democracia está sendo contestada em muitas partes e parece ser incapaz de garantir igualdade de direitos e oportunidades, de representar os anseios populares e de encarnar uma forma de governo partilhado que funcione? Essa proximidade com a democracia pode significar um abraço de afogados para o jornalismo que já não consegue nadar nas águas revoltas da sua crise? Ward não ataca esta questão, mas seu livro reforça a útil ideia de que a ética jornalística pode significar uma zona de contenção. Atender ao convite de romper com a ética tradicional não é trair a deontologia nem o jornalismo. O autor nos acalma: o futuro da ética jornalística depende de pensadores criativos que se disponham a colocar à prova suas propostas e apostas. Seu livro é um incentivo, não um atestado de óbito.

Disrupting Journalism Ethics é o oitavo volume da série Disruptions da editora Routledge, dirigida por Bob Franklin (Universidade de Cardiff, País de Gales), e que se concentra em temas emergentes e desafiadores como as fake news, a publicidade nativa em meios de informação, o uso de drones e a febre dos dispositivos móveis no Oriente Médio.

Diretor do Centro para a Ética Jornalística da Universidade de Wisconsin, em Madison, Estados Unidos, Stephen J. A. Ward é um dos autores mais prolíficos e influentes do lamentavelmente restrito clube de eticistas da área. Apesar disso, seus livros ainda são inéditos no Brasil, o que não serve de desculpa para desconhecer seu pensamento e a potência de suas ideias. Disrupting Journalism Ethics não é a sua contribuição mais robusta e o livro reverbera muitas ideias já apresentadas pelo autor. Não se trata, portanto, de um trabalho absolutamente original. Seu valor maior talvez esteja na oportunidade de seu surgimento. Os dias atuais carecem mais de obras provocativas e potencialmente erráticas do que vetustos tratados que podem envelhecer antes do final do verão.

\section{REFERENNCIAS}

PAUL, Dairan Mathias. Valores morais em atos de jornalismo: reflexões sobre uma ética para não-jornalistas. Dissertação de Mestrado. Florianópolis: Universidade Federal de Santa Catarina, 2017.

STEARNS, Josh. Acts of journalism: defining Press Freedom in the digital age. FreePress, 2013. 
WARD, Stephen; WASSERMAN, Herman. Open ethics: towards a global media ethics of listening. Journalism Studies, v. 16, n. 6, pp. 834-849, 2014.

WARD, Stephen; WASSERMAN, Herman. Towards an open ethics: implications of new media platforms for Global Ethics Discourse. Journal of Mass Media Ethics, v. 25, n. 4, pp. 275-292, 2010.

WARD, Stephen. A theory of patriotism for journalism. IN: WARD, Stephen; WASSERMAN, Herman (eds.). Media ethics beyond borders: a global perspective. New York/London: Routledge, 2010.

WARD, Stephen. Radical media ethics: a global approach. Chichester: Wiley-Blackwell, 2015. 